\title{
GLOBAL OCEAN CIRCULATION AND EQUATOR-POLE HEAT TRANSPORT AS A FUNCTION OF OCEAN GCM RESOLUTION
}

\begin{abstract}
by
Curt Covey

Program for Climate Model Diagnosis and Intercomparison Lawrence Livermore National Laboratory, Livermore, CA, USA
\end{abstract}

June 1994 


\section{DISCLAIMER}

This report was prepared as an account of work sponsored by an agency of the United States Government. Neither the United States Government nor any agency thereof, nor any of their employees, make any warranty, express or implied, or assumes any legal liability or responsibility for the accuracy, completeness, or usefulness of any information, apparatus, product, or process disclosed, or represents that its use would not infringe privately owned rights. Reference herein to any specific commercial product, process, or service by trade name, trademark, manufacturer, or otherwise does not necessarily constitute or imply its endorsement, recommendation, or favoring by the United States Government or any agency thereof. The views and opinions of authors expressed herein do not necessarily state or reflect those of the United States Government or any agency thereof. 


\section{DISCLAIMER}

Portions of this document may be illegible in electronic image products. Images are produced from the best available original document. 


\section{ABSTRACT}

To determine whether resolution of smaller scales is necessary to simulate large-scale ocean climate correctly, I examine results from a global ocean GCM run with horizontal grid spacings spanning a range from coarse resolutions traditionally used in climate modeling to nearly the highest resolution attained with today's computers. This work represents an extension (to lower resolutions) of earlier studies by Semtner and Chervin. The experiments include four cases employing $4^{\circ}, 2^{\circ}, 1^{\circ}$ and $1 / 2^{\circ}$ spacing in latitude and longitude, which were run with minimal differences among them, i.e., in a controlled experiment. Two additional cases $-1 / 2^{\circ}$ spacing with a more scale-selective sub-gridscale mixing of heat and momentum, and approximate $1 / 4^{\circ}$ spacing-are also included. The $1 / 4^{\circ}$ run resolves most of the observed mesoscale eddy energy in the ocean.

Several artificial constraints on the model tend to minimize differences among the different resolution cases. Nevertheless, for quantities of interest to global climate studies the simulations show significant changes as resolution increases. These changes generally but not always bring the model into better agreement with observations. Differences are typically more noticeable when comparing the $4^{\circ}$ and $2^{\circ}$ runs than when comparing the $2^{\circ}$ and $1^{\circ}$ runs or the $1^{\circ}$ and $1 / 2^{\circ}$ runs. A reasonable conclusion to draw for current studies with coupled ocean-atmosphere GCMs is that the ocean grid spacing could be set to about $1^{\circ}$ to accrue the benefits of enhanced resolution without paying an excessively steep price in computer-time cost.

The model's poleward heat transport at $1 / 2^{\circ}$ grid spacing peaks at about $1 \times 10^{15} \mathrm{~W}$ in the Northern Hemisphere and $0.5 \times 10^{15} \mathrm{~W}$ in the Southern Hemisphere. These values are significantly below observations, a problem typical of ocean GCMs even when they are less constrained than in the present study (e.g., when they are coupled to an interactive atmosphere). This problem is alleviated somewhat in the $1 / 4^{\circ}$ run. In this case, however, the eddies resolved by the model generally act to counter rather than to reinforce the heat transport of the mean flow; improved heat transport may result less from enhanced resolution than from other changes made in this version of the model, such as more accurate wind forcing. 


\section{RATIONALE}

Climate simulations with general circulation models (GCMs) suffer from a limitation inherent to any hydrodynamic calculation. To solve partial differential equations on a computer, the fluid continuum must be sampled at a finite number of points, typically a fixed grid. Convergence as resolution is increased is difficult to attain or even test because the amount of computer time required increases rapidly with resolution. The problem is especially worrisome for horizontal resolution in ocean GCMs. Most kinetic energy in ocean currents occurs at horizontal scales less than roughly $50 \mathrm{~km}$, the size of so-called mesoscale eddies (e.g., Figure 6 of Woods, 1985). Global oceanatmosphere GCMs, however, have typically operated with horizontal gridpoint spacings of several hundred kilometers.

This report describes how an ocean GCM behaves as a function of horizontal resolution when used to simulate the present-day climate. The model chosen for this study, developed by Semtner and Chervin $(1988,1992)$, takes advantage of recent supercomputer technology to achieve the greatest horizontal resolution attained to date for a model with global coverage. In this study I compare Semtner and Chervin's simulations, performed at $1 / 2^{\circ}$ grid spacing in latitude and longitude $\left(1 / 2^{\circ} \times 1 / 2^{\circ}\right)$, with simulations at three lower resolutions: $1^{\circ} \times 1^{\circ}, 2^{\circ} \times 2^{\circ}$ and $4^{\circ} \times 4^{\circ}$. The model runs for this comparison were set up with minimal differences other than resolution, i.e., as a controlled experiment or, in terminology of the World Climate Research Program, a "Level II intercomparison." In addition I examine results from a $1 / 2^{\circ} \times 1 / 2^{\circ}$ run with a different, more scale-selective parameterization of subgridscale mixing, which allows more fine structure to develop, and I also briefly examine results from a run with approximately $1 / 4^{\circ}$ grid spacing (Semtner and Chervin, 1993). These two additional runs were performed separately by Semtner and Chervin, who generously provided the results. The $1 / 4^{\circ}$ run in particular is not easy to compare with the Level II runs because of numerous changes made in the model in addition to resolution (see next section). It does, however, give insight into the effects of mesoscale eddies, because the $1 / 4^{\circ}$ run captures essentially all of the eddy activity observed by satellite altimetry.

The present study cannot conclusively determine whether the effects of mesoscale eddies can be neglected (or parameterized) in large-scale climate 
simulations. For GCM climate studies focusing on large spatial scales, however, the key practical question is how much benefit results from the steep costs in computer time that are imposed by increasing a model's resolution (these increase by about a factor of 5 to 6 for each halving of horizontal grid-point spacing for the Semtner-Chervin model when it is run on modestly parallel supercomputers). Increasing resolution in the ocean component must compete with a multitude of other computer-time demands in coupled GCM work. These demands include fully exploring adjustableparameter and initial-condition space, increasing the length of simulations and incorporating related components of the climate system such as the carbon cycle. Accordingly, it is important to gauge how much an ocean GCM's simulation of large-scale climate improves as horizontal resolution increases. That is the principal goal of the present study.

\section{RELATIONSHIP WITH OTHER OCEAN MODEL STUDIES}

R. C. Malone and coworkers (personal communication) have recently completed an additional run of the Semtner-Chervin model at about $1 / 6^{\circ}$. grid spacing, and additional ocean GCM studies of the effect of horizontal resolution have employed equally high resolution. With the exception of the work of Malone et al. (which is not yet completely analyzed), these studies applied to limited domains, and they often employed unrealistic "box-like" geometry for ocean basins and simplified the mechanism of thermohaline circulation by replacing the two conserved variables, temperature and salinity, with a single conserved variable, density (Bryan, 1991). The resolutions employed in this prior work, together with resolutions used in the ocean portion of typical coupled GCMs and in state-of-the-art regional ocean GCMs, are compared in Figure 1 with the resolutions employed in the present study.

Figure 1 locates models in the two-dimensional domain of horizontal grid-point spacing and horizontal momentum diffusion coefficient or "eddy viscosity" (Laplacian $v_{2}$ or biharmonic $v_{4}$; see below). The figure serves as a reminder that one cannot change just resolution in a GCM, leaving all other parameters unchanged. Any GCM must account for scales of circulation smaller than the spacing of its grid points by means of sub-gridscale parameterizations. In practice, the need for computational stability makes it 
impossible to coarsen the resolution of a large-scale fluid dynamics model without increasing its sub-gridscale mixing (nor would it make physical sense to leave this mixing unchanged, for what is "sub-gridscale" changes with grid spacing). In the present study the parameterizations for sub-gridscale horizontal mixing of both heat and momentum change with horizontal resolution. Both are parameterized in the Semtner-Chervin model as downgradient Laplacian $\left(\nabla^{2}\right)$ or biharmonic $\left(\nabla^{4}\right)$ diffusion in a horizontal plane. The diffusion coefficients are spatially constant but increase with grid spacing. Use of the more scale-selective biharmonic diffusion parameterization allows resolution of some mesoscale eddies even at $1 / 2^{\circ} \times 1 / 2^{\circ}$ resolution, mainly at low latitudes (Semtner and Chervin, 1988, 1992). The large $v_{4}$ values in the two highest-resolution Semtner-Chervin runs were needed because of a switch to unsmoothed topography (Semtner, private communication).

The figure shows that the Semtner-Chervin model spans the gap between two traditional classes of ocean model: low-resolution, high-viscosity ocean GCMs intended for climate studies, and high-resolution, low-viscosity models that resolve mesoscale eddies. The latter include pioneering work that resolved mesoscale eddies on a limited domain (Holland and Lin, $1975 \mathrm{a}, \mathrm{b})$ and, recently, more realistic regional models as well as an extremely high-resolution study by Böning and Budich (1992) which adds to the information reviewed by Bryan (1991). The climate-oriented ocean GCMs include the ocean component of an early coupled ocean-atmosphere GCM (Bryan et al., 1975) and the ocean components of two coupled GCMs that recently have been used for forecasts of global warming. The tendency over nearly two decades of modeling work for the ocean components of coupled GCMs to hover in the vicinity of $4^{\circ}$ resolution is strikingly evident. The two points representing recent coupled GCM work come from four models surveyed by Gates et al. (1993). The other two models surveyed by Gates et al. used different types of sub-gridscale parameterizations, which cannot be plotted on Figure 1, but they also have horizontal grid-point spacing in the range $3^{\circ}-5^{\circ}$.

Laplacian diffusion of temperature, not shown in Figure 1, accompanied Laplacian diffusion of momentum in this study. The coefficient $\kappa_{2}$ was set to $1 \times 10^{3} \mathrm{~m}^{2} \mathrm{~s}^{-1}$ at $1 / 2^{\circ} \times 1 / 2^{\circ}$ resolution (Semtner and Chervin, 1988) and increased linearly with grid spacing. As discussed below, the linear increase rule gives values somewhat out of line with Laplacian diffusion 
coefficients used in typical climate-oriented models. Biharmonic diffusion of temperature, with coefficient $\kappa_{4}=-2.5 \times 10^{11} \mathrm{~m}^{4} \mathrm{~s}^{-1}$, accompanied the $1 / 2^{\circ} \mathrm{x}$ $1 / 2^{\circ}$ experiment with biharmonic momentum diffusion. (The values of $\kappa_{4}$ and $v_{4}$ published by Semtner and Chervin (1988) were interchanged due to a typographical error.) For the $1 / 4^{\circ}$ run the sub-gridscale mixing of both momentum and temperature was also biharmonic. The coefficient of momentum mixing was as shown in Figure 1, and the coefficient of heat mixing was $-5 \times 10^{11} \mathrm{~m}^{4} \mathrm{~s}^{-1}$.

The $1 / 4^{\circ}$ run incorporated many changes to the model in addition to resolution. Prominent among these were use of "unsmoothed" topography (which necessitated coefficients of heat and momentum mixing somewhat larger than the $1 / 2^{\circ} \times 1 / 2^{\circ}$ biharmonic-diffusion run), a free-surface as opposed to rigid-lid upper boundary condition, elimination of "robustdiagnostic" forcing in the deep ocean (see below), use of a more recent wind stress data set and seasonal cycle as opposed to annual mean forcing. Also, the grid-point spacing was no longer equal in latitude, but rather varied from about $1 / 5^{\circ}$ at the poleward boundaries to $2 / 5^{\circ}$ at the Equator, with an average of about $1 / 4^{\circ}$. Because of all these changes, results from the $1 / 4^{\circ}$ run are not easily compared with those of the other Semtner-Chervin model runs in terms of the effect of resolution. Results from the $1 / 4^{\circ}$ run are discussed only near the end of this report to make a point about the role of mesoscale eddies in ocean heat transport.

In all Semtner-Chervin model runs, vertical resolution and vertical sub-gridscale mixing was the same as given in Semtner and Chervin (1988). There were 20 levels, unequally spaced with greater vertical resolution near the top and bottom of the model. GCM experiments indicate that this number of vertical levels is adequate to resolve vertical overturning, at least with $2^{\circ} \times 2^{\circ}$ horizontal resolution (Weaver and Sarachik, 1990).

\section{BOUNDARY CONDITIONS AND SPINUP PROCEDURE}

With the exception of the $1 / 4^{\circ}$ run, boundary conditions and spinup procedure were exactly as specified by Semtner and Chervin (1988). The model was forced by annual mean (but spatially varying) observed values of wind stress, temperature and salinity at the surface, and it similarly constrained temperature and salinity near the poles. All model runs were 
brought to steady state by an acceleration procedure known as robustdiagnostic forcing: each case began with zero current and horizontally uniform temperature and salinity, and used artificial Newtonian-relaxation terms in the salinity and thermal energy equations to push salinity and temperature toward observed values. Observed values used in the robustdiagnostic forcing entered at the same relatively coarse resolution in each case. The robust-diagnostic forcing was gradually reduced as spinup proceeded. Each run ended with a 10-year integration with no robustdiagnostic forcing above 700 meters depth, but below this depth a three-yeartimescale relaxation remained. During the final year the rate of change of kinetic energy was only about $1 \%$ of the work done by wind stress, indicating that the integrations had reached steady state (Semtner and Chervin, 1988; Covey, 1992). All results discussed below are averages over that final year, except for the $1 / 4^{\circ}$ run, for which a $32 / 3$ year average is shown (thereby introducing a slight bias in which some months in the seasonal cycle are weighted more heavily than others).

Retention of robust-diagnostic forcing in the deep ocean places an obvious limitation on the results of this study. However, as discussed below, the main conclusions about the effects of resolution on ocean circulation do not seem to be affected by this constraint (Washington et al., 1994).

\section{OCEAN CIRCULATION}

Figures 2-3 show the barotropic transport streamfunction in a horizontal plane. This quantity is defined so that the difference between any two isolines gives the vertically integrated volume transport between them, with higher values to the right and lower values to the left of the flow direction. Figure 2 shows the streamfunction for the four Laplacian-diffusion cases. Here the streamfunction has been regridded to $4^{\circ} \times 4^{\circ}$ in all cases and smoothed with a five-point filter, in order to emphasize the largest scales of circulation. All resolutions (as well as the biharmonic-diffusion cases, not shown in Figure 2) exhibit familiar features of the observed large-scale circulation: subtropical gyres-clockwise in the Northern Hemisphere, counterclockwise in the Southern Hemisphere-together with an eastwardflowing Antarctic Circumpolar Current. Two changes are apparent as horizontal resolution is increased: a modest strengthening of the Kuroshio 
Current off Japan and a significant strengthening of the Antarctic Circumpolar Current. The salient large-scale result is the large difference between the $4^{\circ} \times 4^{\circ}$ results and any other case compared to smaller differences among the $2^{\circ} \times 2^{\circ}, 1^{\circ} \times 1^{\circ}$ and $1 / 2^{\circ} \times 1 / 2^{\circ}$ cases.

Examination of regional details of the streamfunction of course reveals additional sensitivity to resolution. For example, Figure 3 shows this function in the Gulf Stream region, this time displayed in the original gridpoint spacing of each case and not smoothed. Differences among the different resolution cases are more striking. Especially noteworthy are development of a tightly closed "recirculation" in the $1 / 2^{\circ} \times 1 / 2^{\circ}$ cases and the appearance of eddies in the $1 / 2^{\circ} \times 1 / 2^{\circ}$ biharmonic-diffusion case (despite averaging over 1 year), both of which bring the model results into better agreement with observations. However, focusing on larger scales, the character of the circulation varies more dramatically in passing from $4^{\circ}$ to $2^{\circ}$ grid spacing, or from $2^{\circ}$ to $1^{\circ}$, than from $1^{\circ}$ to $1 / 2^{\circ}$.

Similar comments apply to the analogous longitude-integrated "meridional overturning" streamfunction in a vertical plane, shown in Figure 4 (here the sign convention has larger values to the left of flow direction). At $4^{\circ} \times 4^{\circ}$ resolution the overturning is dominated by sinking at the southern boundary associated with a Southern Hemisphere thermally direct circulation of magnitude $\sim 50 \times 10^{6} \mathrm{~m}^{3} \mathrm{~s}^{-1}$. A much weaker counterpart of this circulation is present in the Northern Hemisphere, and wind-driven (Ekman-pumped) cells are present near the surface giving equatorial upwelling and a Southern Hemisphere thermally indirect circulation. The latter is sometimes called a "Deacon cell" (see, e.g., Bryan et al., 1988). As grid spacing is reduced from $4^{\circ}$ to $1^{\circ}$, sinking at the southern boundary nearly vanishes as an expanded Deacon cell confines the formerly dominant Southern Hemisphere thermally direct cell to abyssal depths. At the same time the Northern Hemisphere thermally direct cell expands to $\sim 15 \times 10^{6} \mathrm{~m}^{3}$ $\mathrm{s}^{-1}$, about two-thirds the value observationally deduced for the real ocean's deep "conveyor belt" overturning circulation (Broecker, 1991). As grid spacing is further reduced to $1 / 2^{\circ}$, and effective resolution further increased by introduction of biharmonic diffusion, changes in meridional overturning are much less dramatic. The most noticeable change at these higher resolutions is a reduction in the deep Northern Hemisphere cell back to the magnitude obtained at low resolution. However, the most obvious overall 
change in the simulations takes place as grid-point spacing is reduced from $4^{\circ}$ to $2^{\circ}$, when the egregiously large Southern Hemisphere cell is greatly diminished.

Unfortunately little more can be said about the simulated meridional overturning's agreement with observations. For circulation in a horizontal plane, however, more observations are available. Nearly global coverage at large time and space scales is available for surface currents inferred from ship drifts (Meehl, 1982). Though this data set suffers from systematic errors due to the wind's contribution to ship drifts, it is instructive to compare it with model-simulated surface currents. As shown in Figure 5, even the $1 / 2^{\circ} \times 1 / 2^{\circ}$ biharmonic-diffusion run, which exhibits a relatively vigorous horizontal circulation, has surface currents generally more sluggish than observed except near the Equator (there a different problem is apparent: the simulated currents in the Pacific are too divergent). The problem with the model's simulation may simply be that the "surface" current is actually taken at the model's uppermost level, at 25 meters depth. Considering the vertical integral of horizontal circulation, Figure 6 gives flow through selected areas (i.e., point values of the barotropic streamfunction shown in Figures 2-3) where observations exist. Flow through the Drake Passage between South America and Antarctica intensifies with increasing resolution and appears to asymptote at nearly twice its observed value (Whitworth and Nowlin, 1987). Flow in the Kuroshio current off Japan strengthens with increasing resolution to its observed order of magnitude (Masuzawa, 1972, Figure 2), while flow in the Gulf Stream remains below its observed value (Stommel, 1965, Figure 6; Krauss et al., 1990) for all resolutions studied. Southwestward transport between Indonesia and Australia is near its observed value (Godfrey, 1989; Macdonald, 1993) for all resolutions studied. It should be noted that the "observations" are inferred for the most part from sparse measurements of temperature and salinity together with an assumption of geostrophic balance.

\section{MERIDIONAL HEAT TRANSPORT}

For climate studies the most important role of the ocean involves not circulation per se, but the transport and storage of heat. In this study, which is confined to annual mean simulations of the present-day climate, the relevant 
quantity is heat exchanged horizontally. Figures 7-9 show the three components that make up north-south heat transport: explicit advection by the time-mean circulation, explicit advection by eddies, and mixing at scales below the grid resolution. The components are defined as follows. Explicit advection is proportional to north-south current velocity $v$ and temperature $T$, and divides into time-mean and eddy components according to $\nu T=\bar{v} \bar{T}+\overline{v^{\prime} T^{\prime}}$, where the overbar denotes a time-mean and the prime denotes departure from the time-mean. As noted above, horizontal sub-gridscale heat transport is accomplished in this study by Laplacian or biharmonic diffusion: a term $\kappa_{2} \nabla^{2} T$ or $\kappa_{4} \nabla^{4} T$ contributes to the rate of change of temperature. Because $\nabla^{2}$ is the divergence of the gradient operator and $\nabla^{4} \equiv \nabla^{2}\left(\nabla^{2}\right)$, $\kappa_{2} \nabla^{2} T$ or $\kappa_{4} \nabla^{4} T$ implies diffusive heat transport proportional to the horizontal gradient of $T$ or of $\nabla^{2} T$, respectively.

Figure 7 shows the longitude- and depth-integrated north-south heat transport due to explicit advection by the time-mean flow, for resolutions as fine as $1 / 2^{\circ}$. Most of this part of the transport is due to the meridional overturning circulation, with a smaller proportion associated with the longitudinally asymmetric "gyre" circulation (Covey, 1992). The sign of the transport is toward the Poles (down the gradient of temperature) at almost all latitudes except in the higher-resolution runs. For these cases the transport is toward the Equator at $\sim 45^{\circ} \mathrm{S}$. This latitude is approximately the location of the thermally indirect Deacon Cell prominent at higher resolutions (Figure 4). In addition to reversing the transport's direction at this latitude, increasing resolution also decreases the magnitude of poleward heat transport in the Southern Hemisphere north and south of the Deacon Cell. In the Northern Hemisphere, there is much less effect of resolution on the heat transport due to explicit advection by the time-mean flow.

Figure 8 shows the analogous contribution to heat transport by explicitly simulated eddies. This component becomes significant only at the highest resolutions and at low latitudes, because the scale of mesoscale eddies is roughly the Rossby radius of deformation, inversely proportional to the sine of latitude. As resolution is increased by passing from $1^{\circ}$ to $1 / 2^{\circ}$ grid spacing, and again increased (in effect) in passing from Laplacian to biharmonic diffusion in the $1 / 2^{\circ} \times 1 / 2^{\circ}$ case, the eddy heat transport that builds up is directed almost entirely toward the Equator. This eddy transport 
would counteract any tendency of time-mean circulation to increase poleward heat transport as resolution is increased, in accord with the compensation mechanism observed in simplified box-model studies (Bryan, 1991; Böning and Budich, 1992). However, reference to Figure 7 shows that in the present study, the time-mean circulation does not simply increase its poleward heat transport as resolution is increased. Further insight into this matter comes from eddy transports in the $1 / 4^{\circ}$ run, which are discussed separately below.

Figure 9 shows the contribution of sub-gridscale heat mixing. This part of the transport is of course down-gradient at all latitudes, which means poleward for the most part, and it decreases in magnitude as resolution is increased. For the biharmonic-diffusion $1 / 2^{\circ} \times 1 / 2^{\circ}$ case, sub-gridscale mixing of heat is utterly negligible compared with explicitly simulated advection. In the other runs, which use Laplacian diffusion, sub-gridscale heat transport is approximately proportional to grid spacing, because the equator-to-pole distribution of ocean temperature (with a particularly sharp gradient in the Southern Ocean) is relatively insensitive to resolution, while the coefficient $\kappa_{2}$ increases linearly with grid spacing. In the middle latitudes of the Southern Hemisphere, sub-gridscale mixing transports more heat than explicitly simulated advection when grid spacing is larger than about $1^{\circ}$. When grid spacing becomes as large as $4^{\circ}$-the resolution traditionally used in coupled ocean-atmosphere GCM studies-sub-gridscale mixing becomes responsible for at least as much heat transport as explicitly simulated advection at most latitudes.

Figure 10 shows the combination of all heat transport terms for all ocean basins, and for the Atlantic basin alone (Atlantic transports south of $35^{\circ} \mathrm{S}$, the southern tip of Africa, are not shown because the basin is not closed in this region). This figure includes results from the $1 / 4^{\circ}$ run of the model in addition to the $4^{\circ}, 2^{\circ}, 1^{\circ}$ and $1 / 2^{\circ}$ runs discussed above. Leaving aside for the moment the $1 / 4^{\circ}$ results, the most prominent feature in Figure 10 is a markedly greater sensitivity to resolution in the Southern Hemisphere than in the Northern Hemisphere. In southern midlatitudes, as shown above, total poleward heat transport is strongly dependent on the sub-gridscale diffusion component, which is approximately proportional to grid spacing through the coefficient $\kappa_{2}$. The choice in this study to make $\kappa_{2}$ proportional to grid spacing is rather arbitrary; other choices could reduce the changes in southern midlatitude heat transport as resolution is varied. For example, 
Meehl et al. (1982; see their Figure 7a) obtain from a $5^{\circ} \times 5^{\circ}$ ocean GCM the same unrealistically large magnitude of poleward heat transport in the Southern midlatitudes as in the $4^{\circ}$ case shown in Figure 10 (for the total over all basins). Meehl et al. show that their heat transport can be reduced to more reasonable values, however, by simply decreasing $\kappa_{2}$ from $2 \times 10^{4} \mathrm{~m}^{2} \mathrm{~s}^{-1}$ to $2 \mathrm{x}$ $10^{3} \mathrm{~m}^{2} \mathrm{~s}^{-1}$ without changing model resolution (see their Figure 9). Recall that $\kappa_{2}$ used in the present $4^{\circ}$ case is $8 \times 10^{3} \mathrm{~m}^{2} \mathrm{~s}^{-1}$, close to the value that gave Meehl et al. their excessively large transport. However, the heat transport summed over all basins also exhibits a strong resolution dependence at $0-10^{\circ} \mathrm{S}$ due to the explicit advection term (Figure 7). The reason that heat transport at $0-10^{\circ} \mathrm{S}$ maximizes at $2^{\circ} \times 2^{\circ}$ resolution is unclear; the effect arises from the gyre component (see Figure 11 of Covey, 1992). Turning attention to heat transport in the Atlantic basin alone, there is again lack of convergence in the Southern Hemisphere, though South Atlantic heat transport does improve with increasing resolution, giving northward heat transport at most latitudes, as is observed, for both $1 / 2^{\circ} \times 1 / 2^{\circ}$ cases. As in the total over all basins, Atlantic convergence is most apparent in northern midlatitudes (aside from the $1 / 4^{\circ}$ case). This result demonstrates separate convergence in the Atlantic and Pacific at these latitudes, as the Indian basin does not extend that far north.

Also shown in Figure 10 are several sets of "observed" data points. Most of these are not direct observations of the correlation of $v$ and $T$, but rather indirect estimates using the annual mean energy flux into or out of the sea surface. This procedure involves considerable uncertainty (Gleckler, 1993), as is evidenced by the wide divergence of data points from different investigators. Nevertheless there is a tendency for more recent studies to obtain smaller magnitudes of ocean heat transport. Carissimo, Oort and Vonder Haar (1985) deduced sea surface fluxes from (1) top-of-atmosphere energy fluxes measured from satellites and (2) atmospheric energy transport inferred from weather balloon data. Trenberth and Solomon (1994) performed essentially the same calculation but used atmospheric data that had been made dynamically consistent by "assimilation" in an atmospheric GCM. Trenberth and Solomon's heat transports agree both with those obtained using more direct measurements of sea surface fluxes (e.g., Hastenrath, 1982) and with a reanalysis of the Carissimo et al. data set (Savijärvi, 1988), supporting earlier suggestions that the weather balloon data 
underestimates atmospheric heat transport and thus its use overestimates ocean heat transport (Covey, 1988). However, even the smaller values of observed ocean heat transport are generally a factor of two greater than the model-simulated transports at $1 / 2^{\circ}$ resolution.

Only at $1 / 4^{\circ}$ resolution do the model-simulated transports approach the observed values, and only then in the Northern Hemisphere. It might seem that these results demonstrate a need to attain approximately $1 / 4^{\circ}$ resolution in order to resolve mesoscale eddies that boost poleward heat transport up to observed values. Indeed, weak heat transport is a typical problem in climate-oriented coarse-resolution ocean GCMs, including those lacking robust-diagnostic forcing and coupled to atmosphere models (see Figure 8 of Gates et al., 1993). However, for the $1 / 4^{\circ}$ Semtner-Chervin model, as in the case of earlier simplified ocean GCMs discussed above, the effect of eddies is generally to transport heat equatorward, countering rather than reinforcing the heat transport of the time-mean flow. Figure 11, explicitly showing the time-mean and resolved-eddy contributions to $1 / 4^{\circ}$ heat transport, shows this effect quite dramatically. The low-latitude eddy transport is not much different from its counterpart in the $1 / 2^{\circ} \times 1 / 2^{\circ}$ case with biharmonic diffusion (cf. Figure 8). Only at high latitudes is there a weak reinforcement of the time-mean and eddy components; elsewhere they are nearly mirror images of each other.

\section{CONCLUSIONS}

It must be kept in mind that differences among the four resolution cases $4^{\circ} \times 4^{\circ}, 2^{\circ} \times 2^{\circ}, 1^{\circ} \times 1^{\circ}$ and $1 / 2^{\circ} \times 1 / 2^{\circ}$ are artificially minimized. As mentioned above, the deep ocean is pushed toward observed values of temperature and salinity by nonphysical Newtonian relaxation terms added to the conservation equations for heat and salt. An assessment of the effect of this robust-diagnostic forcing on large-scale circulation simulated by an ocean GCM is provided by the study of Toggweiler et al. (1989). From their Figure 4, it appears that the main effect of robust-diagnostic terms is to diminish the magnitude of overturning by up to one-third, but not to change locations of deep water formation. If the effect is similar at different resolutions then it should not present great difficulties in assessing convergence, or lack thereof, in the "Level II" part of this study. Perhaps a more severe constraint is that 
the model's boundary conditions essentially pin temperature and salinity to observations at the sea surface, and at high latitudes (rather than explicitly calculating sea ice behavior and bottom water formation). In any case, by constraining temperature and salinity, the model places restrictions on how much the geostrophic component of circulation can vary. To the extent that surface and deep circulations are coupled, Newtonian forcing of the deep ocean could even affect the surface currents. In the case of Semtner and Chervin's model, however, recent work by Semtner and Chervin (1993) and by Washington et al. (1994; see their Figure 6) shows that the circulations presented in Figures 2-3 are not appreciably different when robust-diagnostic forcing is removed and (in the case of Washington's study) the model is integrated for a further 100 simulated years. Finally, because the surface boundary condition on salinity fixes salt amount rather than freshwater flux, salt transport cannot interact with heat transport through changes in surface buoyancy.

Despite the foregoing constraints, there are important changes in the simulated ocean climate as model resolution increases. The circulation in a horizontal plane becomes more vigorous and typically (though not always) agrees better with observations. In a vertical plane, meridional overturning becomes more realistic by losing the egregiously strong Southern Hemisphere cell present at $4^{\circ}$ grid spacing; the magnitude of overturning at higher resolutions is within a factor of two of the limited observational data. The heat transport between the Equator and the Poles also shows improvement with increasing resolution. Clearly excessive heat transport in the Southern Hemisphere is eliminated when grid spacing drops below $2^{\circ}$ (however, the heat transport at higher resolutions seems too weak, even considering the great uncertainty in observational data). Considering the present results as a whole, changes in large-scale circulation and heat transport are more obvious when grid spacing decreases from $4^{\circ}$ to $2^{\circ}$ to $1^{\circ}$-and especially between $4^{\circ}$ to $2^{\circ}$-than when grid spacing decreases from $1^{\circ}$ to $1 / 2^{\circ}$. "Convergence" is too strong a word to use to describe these results. Still, it is fair to say that there are diminishing returns on the substantial computer time investment required by very high resolution. A reasonable conclusion to draw for current studies with coupled ocean-atmosphere GCMs is that the ocean grid spacing might profitably be set at about $1^{\circ}$ to accrue the benefits of higherthan-traditional resolution without making the calculation intractable (e.g., 
Washington et al., 1994).

Of course these comments apply only to the largest scales of circulation. To simulate small scales the need for high resolution is obvious, and even fairly large regional scales of climate may require high-resolution ocean modeling for proper representation. For example, in a high-resolution model currents could be stronger, but narrower, while transporting the same amount of heat as in a lower resolution model. Thus high resolution in the ocean might be needed for a coupled ocean-atmosphere GCM to adequately represent land-sea contrasts near currents such as the Gulf Stream.

There remains also the question of mesoscale eddies. As noted above, the highest-resolution run of the Semtner-Chervin model discussed in the present study $\left(\sim 1 / 4^{\circ}\right)$, which exhibits sufficient eddy kinetic energy to match satellite observations, shows the best agreement with heat transport observations, but the enhanced poleward heat flow in this case seems to appear despite rather than because of the eddies (and in any case it occurs only in the Northern Hemisphere). Evidently the enhanced agreement with observations is due to one of the many other changes made in the $1 / 4^{\circ}$ model, such as more accurate wind forcing. Nevertheless, when considered together with results from simplified models with even higher resolutions e.g., $1 / 6^{\circ} \times 1 / 5^{\circ}$ in latitude and longitude (Böning and Budich, 1992)-the $1 / 4^{\circ}$ Semtner-Chervin results provide useful information. In both types of model the appearance of mesoscale eddies at higher resolution counteracts total poleward ocean heat transport by the mean flow. It would seem, then, that including mesoscale eddies could not dramatically increase ocean heat. transport beyond the levels simulated in this study. However, it may be that $1 / 4^{\circ}$ grid spacing is inadequate to fully resolve eddy effects despite its agreement with observed eddy kinetic energy. The reinforcement in this case of eddy and mean-flow heat transports at high latitudes (Figure 11), where the eddy scale is smallest, is intriguing, as are results from a new sub-gridscale parameterization of eddy heat transport (Gent and McWilliams, 1990), which makes the poleward heat transport in a coarse-resolution ocean GCM agree better with observations (Danabasoglu et al., 1994). Examination of the $1 / 6^{\circ}$ Semtner-Chervin results, when they are available, may illuminate the situation. Only fully eddy-resolving calculations with global coverageeventually including climatic change as well as the steady state-can unambiguously determine whether or not the effects of mesoscale eddies can 
be neglected or parameterized for the purpose of large-scale climate simulation.

\section{ACKNOWLEDGMENTS}

W. Lawrence Gates originally suggested this study. Albert J. Semtner, Jr., and Robert M. Chervin generously contributed their model, extensive advice on its use and interpretation, and data products from their highresolution runs. Lisa Corsetti provided essential programming assistance. Kevin E. Trenberth provided ocean heat transport data in advance of publication, and Peter Gleckler provided advice on the uncertainties in such estimates. My sincere thanks go to all of the above. This work was performed under auspices of the U.S. Department of Energy's Environmental Sciences Division by the Lawrence Livermore National Laboratory under Contract W7405-ENG-48. 


\section{REFERENCES}

Aagaard, K. and P. Greisman, 1975: Toward new mass and heat budgets for the Arctic Ocean. J. Geophys. Res., 80: 3821-3827.

Beckmann, A., C.W. Böning, C. K. Köberle and J. Willebrand, 1994: Effects of increased horizontal resolution in a simulation of the North Atlantic Ocean. J. Phys. Oceanogr., in press.

Böning, C.W. and R.G. Budich, 1992: Eddy dynamics in a primitive equation model: Sensitivity to horizontal resolution and friction. J. Phys. Oceanogr. 22, 361-381.

Broecker, W.S., 1991: The great ocean conveyor. Oceanography, 4, 79-89

Bryan, K., S. Manabe and R.K. Pacanowski, 1975: A global ocean-atmosphere climate model. Part II. The oceanic circulation. J. Phys. Oceanogr., 5, 30-46.

Bryden, H. L., D. H. Roemmich and J. A. Church, 1991: Ocean heat transport across $24^{\circ} \mathrm{N}$ in the Pacific. Deep Sea Res., 38, 297-324.

Bryan, K., 1991: Poleward heat transport in the ocean. Tellus, 43AB, 104-115.

Carissimo, B.C., A.H. Oort and T.H. Vonder Haar, 1985: Estimating the meridional energy transports in the atmosphere and ocean. J. Phys. Oceanogr., 15, 82-91.

Covey, C., 1988: Atmospheric and oceanic heat transport: simulations versus observations. Climatic Change, 13, 149-159.

Covey, C., 1992: Behavior of an Ocean General Circulation Model at Four Different Horizontal Resolutions, Report No. 4, Program for Climate Model Diagnosis and Intercomparison (Lawrence Livermore National Laboratory, Livermore, CA), 29pp. 
Danabasoglu, G. , J. C. McWilliams and P. R. Gent, 1994: The role of mesoscale tracer transports in the global ocean circulation, Science, submitted.

de Cuevas, B.A., 1993: The Main Runs and Datasets of the Fine Resolution Antarctic Model Project (FRAM). Part II: the Fine Resolution Runs. Internal Document 318, Institute of Oceanographic Sciences Deacon Laboratory, Wormley, UK.

Gates, W. L., U. Cubasch, G. A. Meehl, J. F. B. Mitchell and R. J. Stouffer, 1993:

An Intercomparison of Selected Features of the Control Climates Simulated by Coupled Ocean-Atmosphere General Circulation Models, Steering Group on Global Climate Modelling, World Meteorological Organization Report TD-No. 574 (WCRP-82), Geneva.

Gleckler, P., 1993: The Partitioning of Meridional Heat Transport Between the Ocean and the Atmosphere, Ph.D. thesis, University of California, Davis, CA

Gent, P.R. and J.C. McWilliams, 1990: Isopycnal mixing in ocean circulation models. J. Phys. Oceanogr., 20, 150-155.

Godfrey, J.S., 1989: A Sverdrup model of the depth-integrated flow for the ocean allowing for island circulations, Geophys. Astrophys. Fluid Dynamics, 45, 98-112.

Hall, M. M. and H. L. Bryden, 1982: Direct estimates and mechanisms of ocean heat transport, Deep Sea Res., 29, 339-359.

Hastenrath, S., 1982: On meridional heat transports in the World Ocean. J. Phys. Oceanogr., 12, 922-927.

Holland, W.R. and L.B. Lin, 1975a: On the generation of mesoscale eddies and their contribution to the oceanic general circulation. I. A preliminary numerical experiment. J. Phys. Oceanogr., 5, 642-657.

Holland, W.R. and L.B. Lin, 1975b: On the generation of mesoscale eddies and 
their contribution to the oceanic general circulation. II. A parameter study. J. Phys. Oceanogr., 5, 658-669.

Krauss, W., R. H. Käse and H.-H. Hinrichsen, 1990: The branching of the Gulf Stream Southeast of the Grand Banks. J. Geophys. Res., 95, 13089-13103.

Macdonald, A.M., 1993: Property fluxes at $30^{\circ} \mathrm{S}$ and their implications for the Pacific-Indian throughflow and the global heat budget. J. Geophys. Res., 98, 6851-6868.

Masuzawa, J., 1972: in Kuroshio: Physical Aspects of the Japan Current, $\mathrm{H}$. Stommel and K. Yoshida, Eds. (University of Washington Press, Seattle), pp. 95-127.

Meehl, G.A., 1982: Characteristics of surface current flow interred from a global ocean current data set. J. Phys. Oceanogr., 12, 538-555.

Meehl, G.A., W.M. Washington and A.J. Semtner, Jr., 1982: Experiments with a global ocean model driven by observed atmospheric forcing. J. Phys. Oceanogr., 12, 301-312.

Murray, J.W., 1992: A Prediction of the Transient Response of Climate. Research Technical Note No. 32, the Hadley Center for Climate Research and Prediction, Reading, UK.

Semtner, A.J., Jr., and R.M. Chervin, 1988: A simulation of the global ocean circulation with resolved eddies. J. Geophys. Res., 93, 15502-15522.

Semtner, A.J., Jr., and R.M. Chervin, 1992: Ocean general circulation from a global eddy-resolving model. J. Geophys. Res., 97, 5493-5550.

Semtner, A.J., Jr., and R.M. Chervin, 1993: Southern Hemisphere prognostic results from a global high-resolution ocean model. Fourth International Conference on Southern Hemisphere Meteorology and Oceanography (abstracts), American Meteorological Society, Boston, pp. 26-27. 
Toggweiler, J.R., K. Dixon and K. Bryan, 1989: Simulations of radiocarbon in a coarse-resolution world ocean model. 1. Steady state prebomb distributions. J Geophys. Res., 94, 8217-8242.

Savijärvi, H. I., 1988: Global energy and moisture budgets from rawinsonde data. Month. Weath. Rev., 116, 417-430.

Stommel, H., 1965: The Gulf Stream: A Physical and Dynamical Description (University of California Press, Berkeley, ed. 2), 248pp.

Trenberth, K.E. and A. Solomon, 1994: The global heat balance: Heat transports in the atmosphere and ocean, Climate Dynamics, submitted.

Washington, W.M. and G.A. Meehl, 1989: Climate sensitivity due to increased $\mathrm{CO}_{2}$ : experiments with a coupled atmosphere and ocean general circulation model. Climate Dynamics, 4, 1-38.

Washington, W.M., G.A. Meehl, L. VerPlank and T.W. Bettge, 1994: A world ocean model for greenhouse sensitivity studies: Resolution intercomparison and the role of diagnostic forcing. Climate Dynamics, in press.

Weaver, A.J. and E.S. Sarachik, 1990: On the importance of vertical resolution in certain ocean general circulation models. J. Phys. Oceanogr. 20,600-609.

Whitworth, T., III and W. D. Nowlin, Jr., 1987: Water masses and currents of the Southern Ocean at the Greenwich Meridian. J. Geophys. Res., 92, 64626476.

Woods, J.D., 1985: The World Ocean Circulation Experiment. Nature, 314, 501-511. 


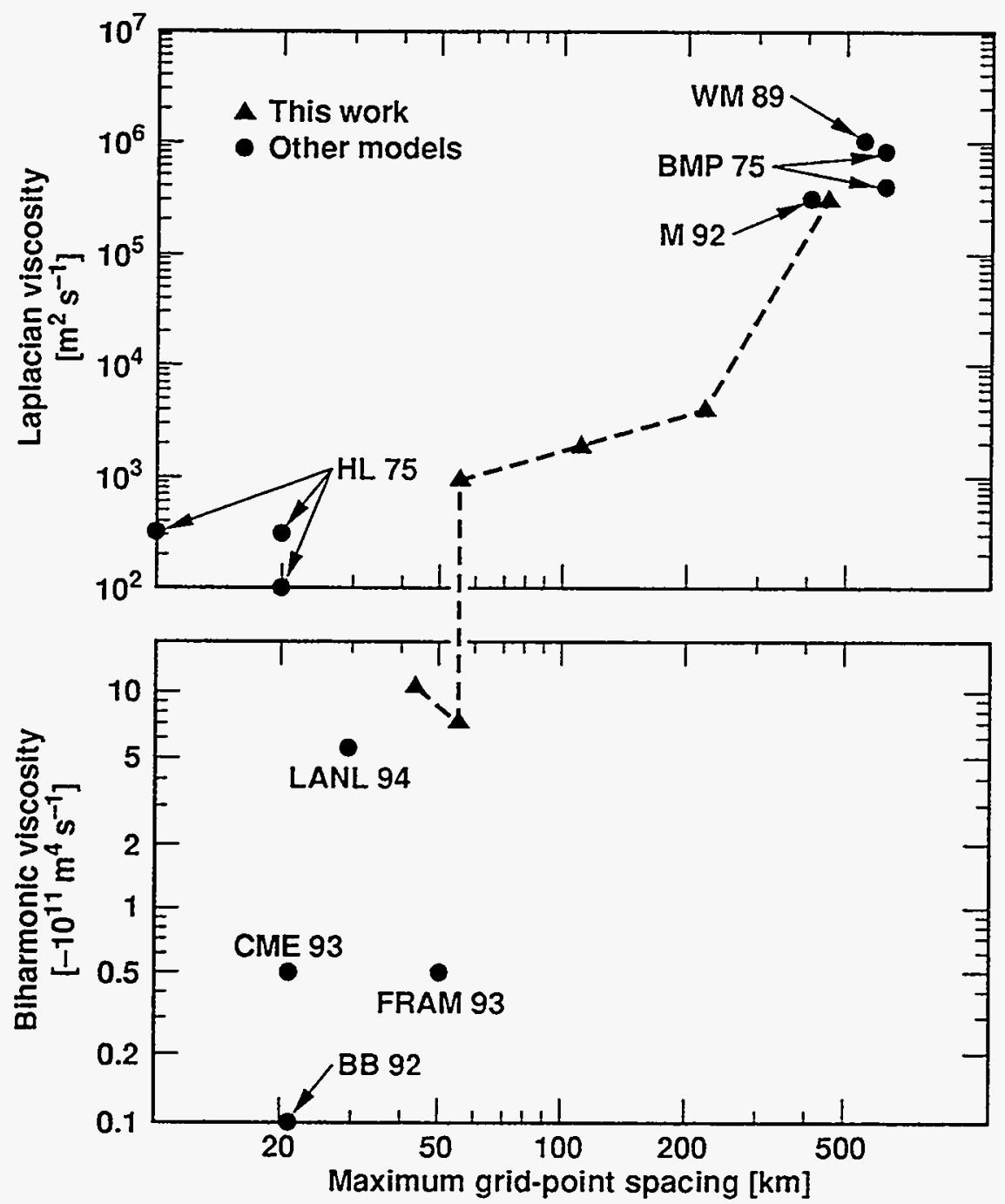

Figure 1: Horizontal spacing of grid points and Laplacian (top frame) or biharmonic (bottom frame) sub-gridscale viscosity coefficients for selected ocean GCMs. Semtner-Chervin model runs analyzed in this study are denoted by triangles, and examples of other ocean GCM work are denoted by circles. For Laplacian viscosity these are taken from Bryan, Manabe and Pacanowski (1975; labeled BMP75), Holland and Lin (1975a,b; labeled HL75), Murray (1992; labeled M92) and Washington and Meehl (1989; labeled WM89). For biharmonic viscosity these are taken from Böning and Budich (1992; labeled BB92), the Community Modeling Experiment of the World Ocean Circulation Experiment (Beckmann et al., 1994; labeled CME93), the Fine Resolution Antarctic Model (de Cuevas, 1993; labeled FRAM93) and a very high resolution run of the Semtner-Chervin model recently completed at the Los Alamos National Laboratory (R. C. Malone et al., personal communication; labeled LANL 94). 
$4 \times 4$

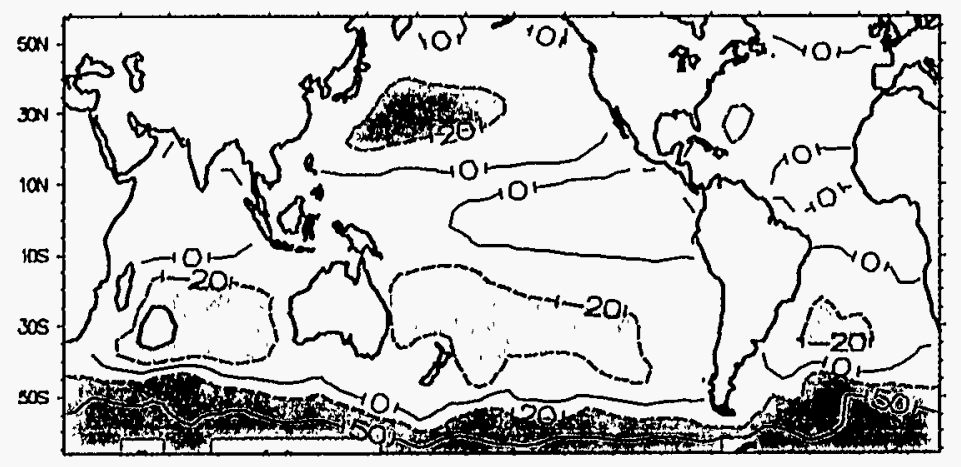

$2 \times 2$

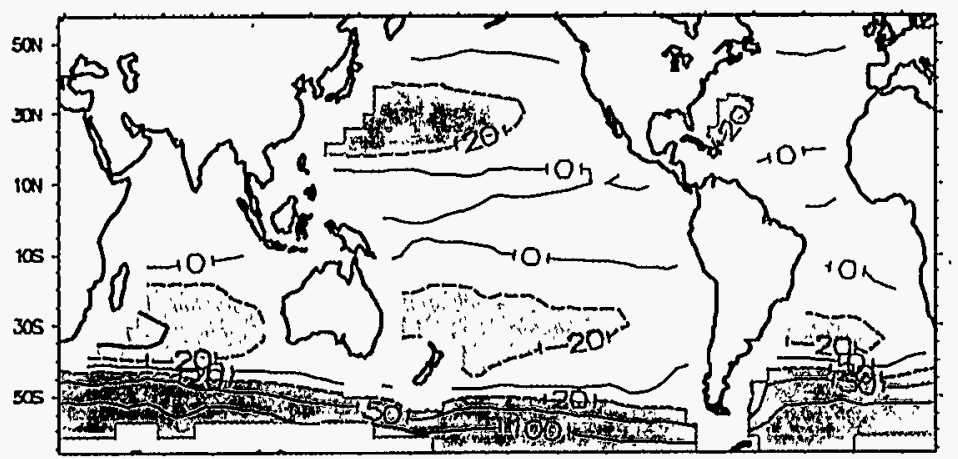

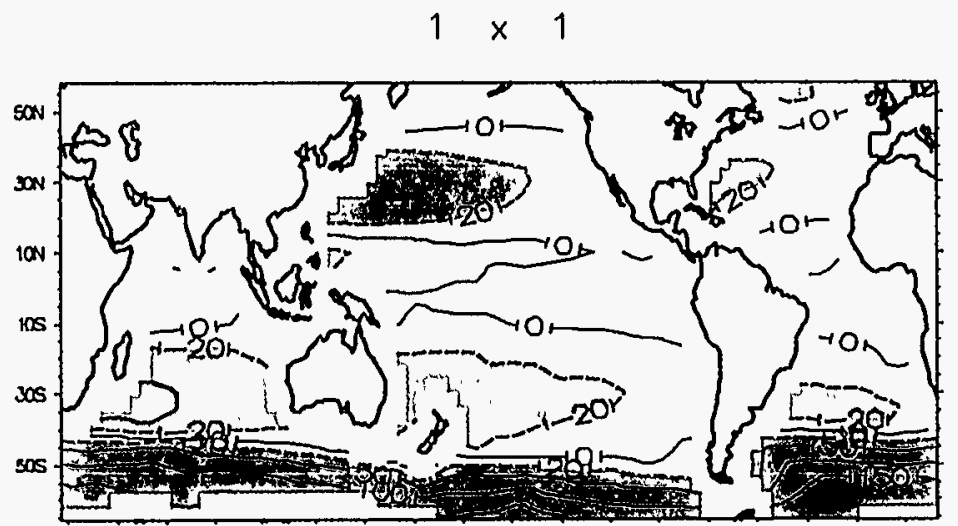

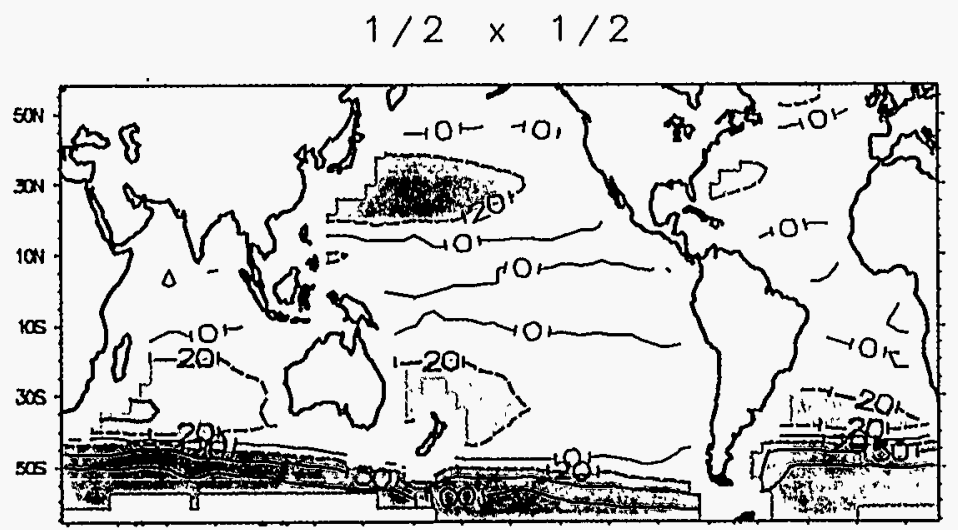

Figure 2: Barotropic streamfunction for the Level II intercomparison runs. Results are regridded to the coarsest resolution (4 $\left.4^{\circ} \times 4^{\circ}\right)$ and smoothed with a 5-point filter to isolate the largest-scale features. Solid contour lines are drawn at intervals of $50 \times 10^{6} \mathrm{~m}^{3} \mathrm{~s}^{-1}$; areas less than $-20 \times 10^{6} \mathrm{~m}^{3} \mathrm{~s}^{-1}$ and greater than $20 \times 10^{6} \mathrm{~m}^{3} \mathrm{~s}^{-1}$ are colored red and blue, respectively, to identify subtropical gyres and the Antarctic Circumpolar Current. 

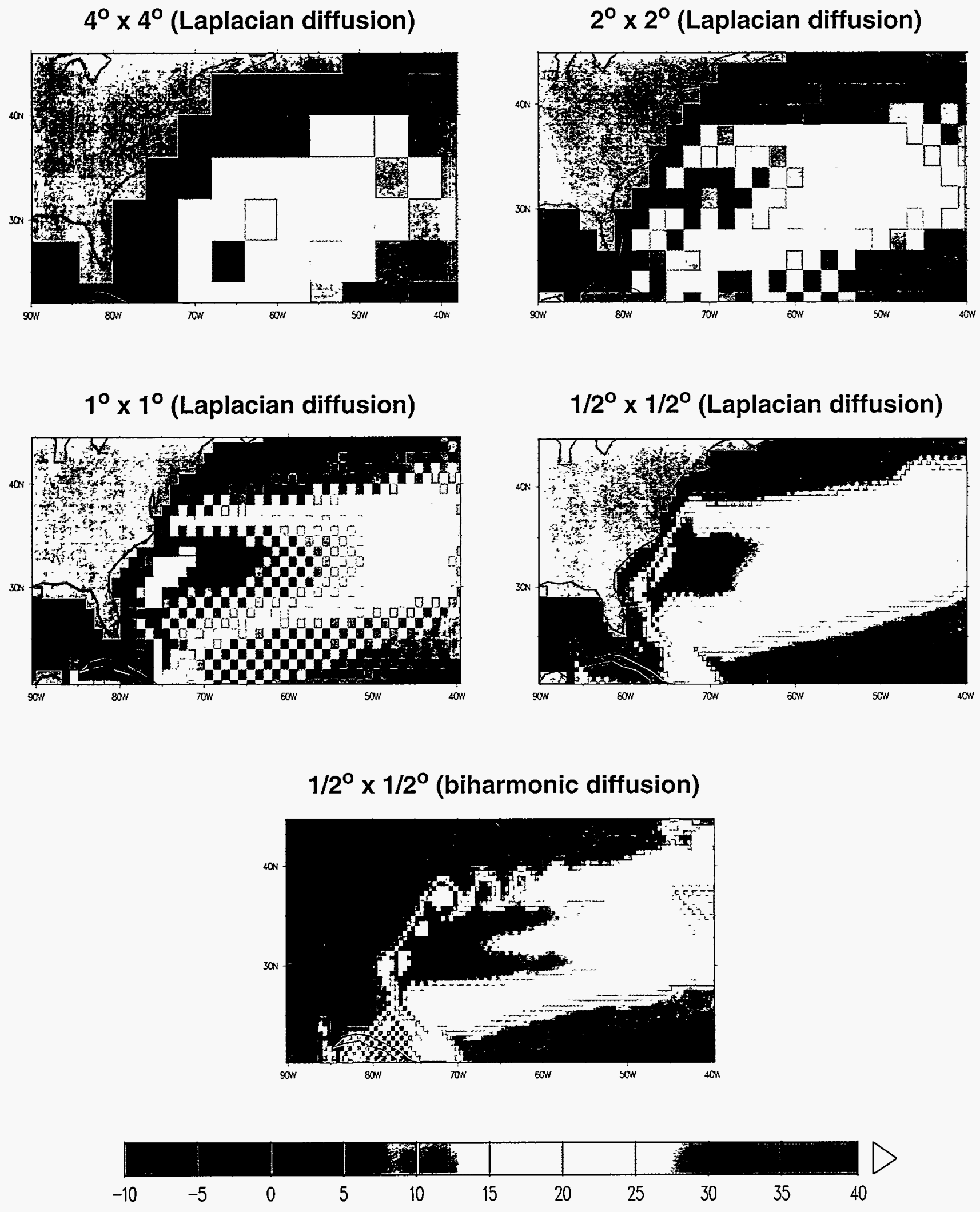

Figure 3: Barotropic streamfunction for resolutions up to $1 / 2^{\circ} \times 1 / 2^{\circ}$ in the Gulf Stream region. 


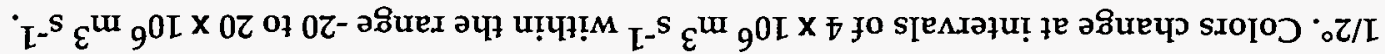
$x$ oz/L of dn suo!̣n
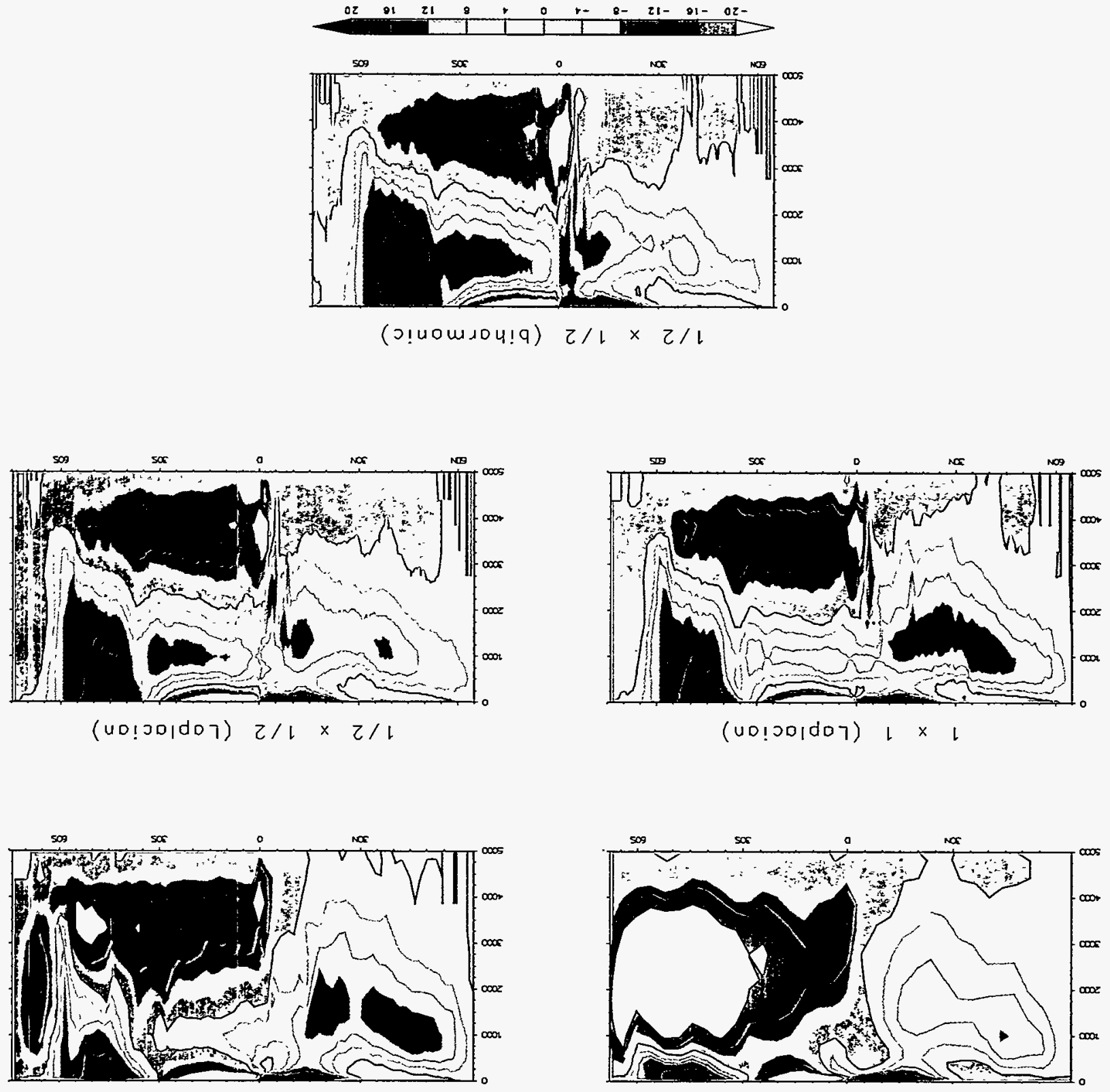

(Uס!วס|dסר) 乙 $\times$ 乙

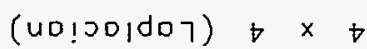




\section{$1 / 2 \times 1 / 2$ (biharmonic)}
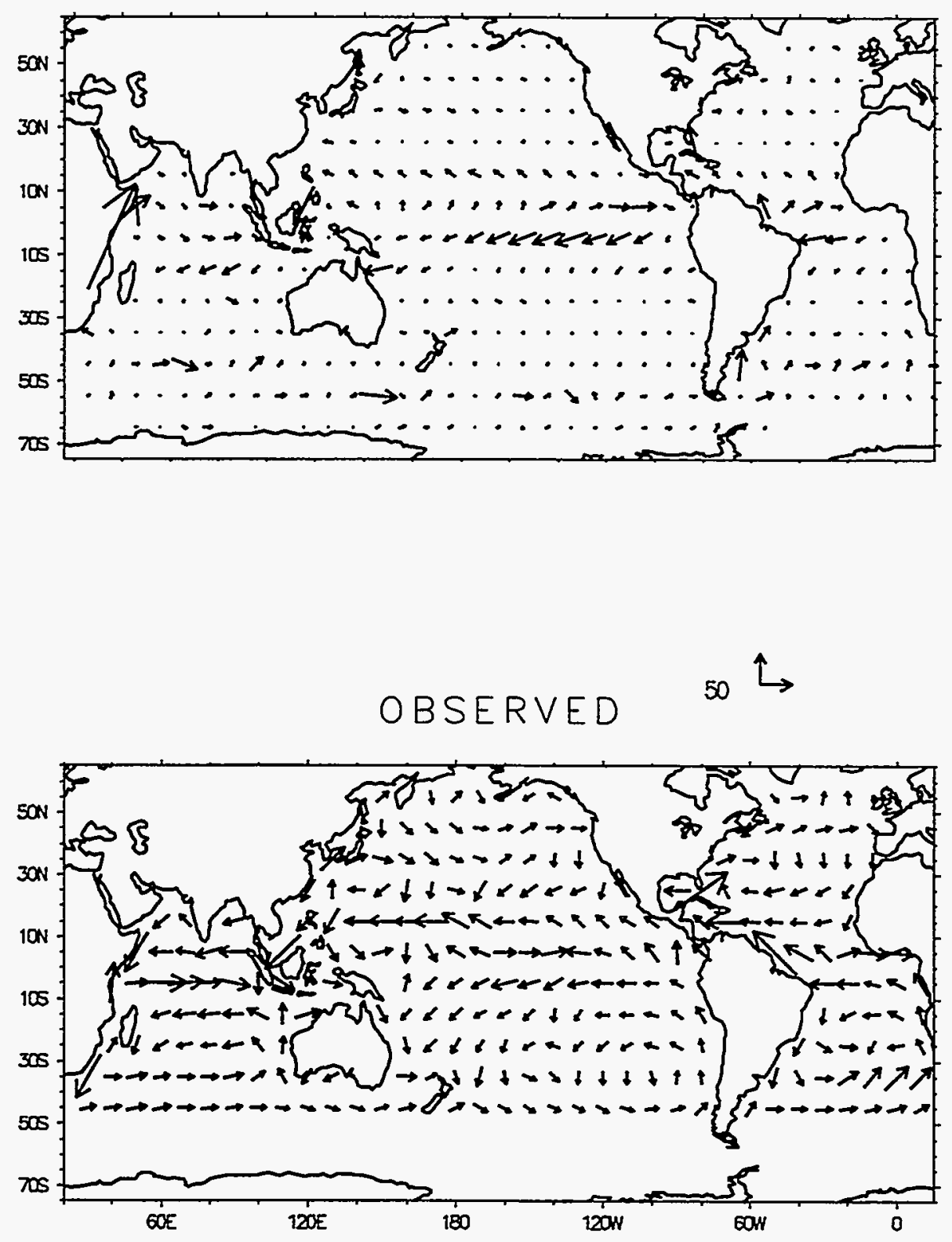

Figure 5: Surface currents modeled in the $1 / 2^{\circ} \times 1 / 2^{\circ}$ run with biharmonic sub-gridscale diffusion compared with observations from ship drifts (Meehl, 1982). Vector scale is $50 \mathrm{~cm} \mathrm{~s}^{-1}$. 


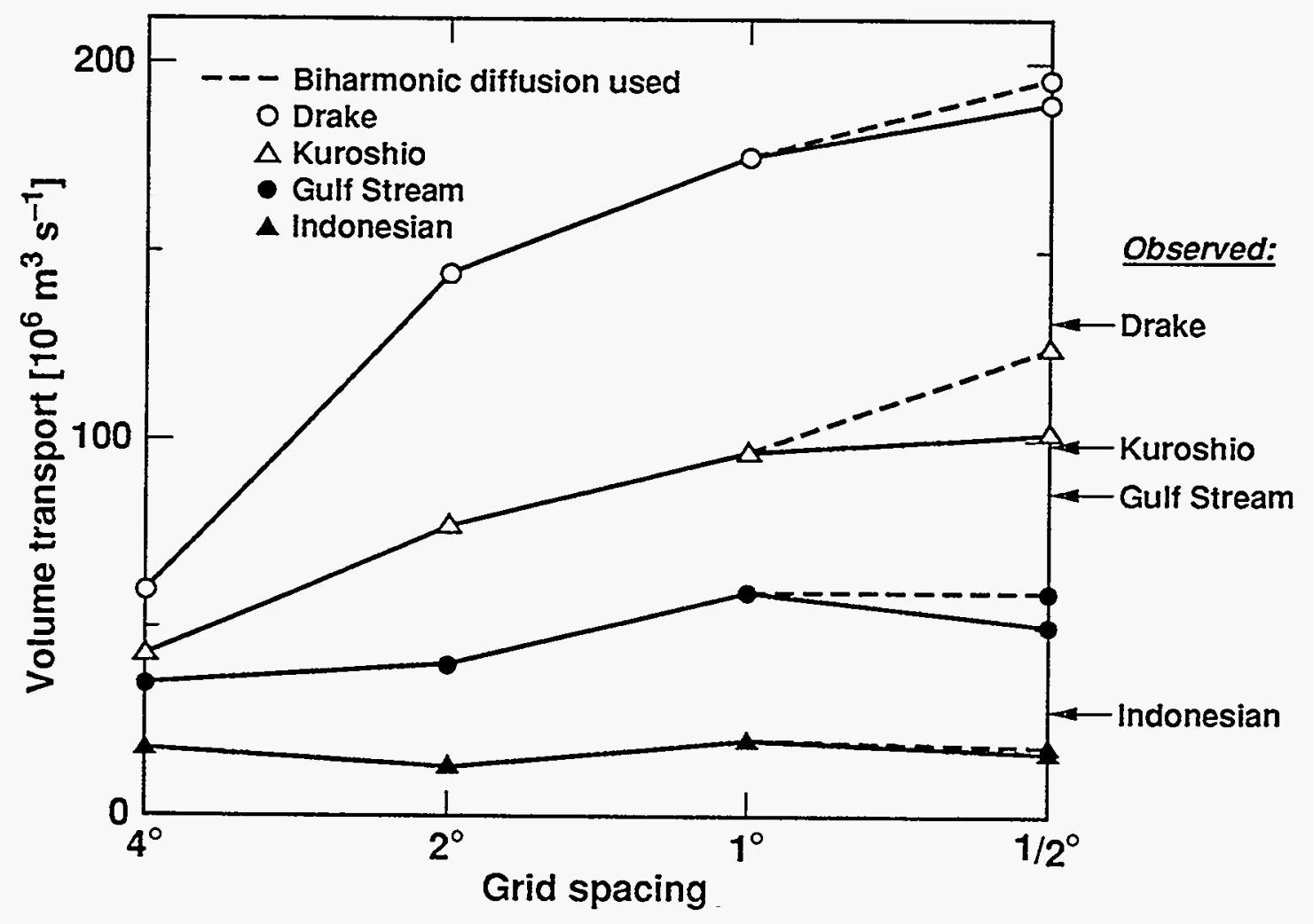

Figure 6: Volume transports through indicated straits and western boundary currents as a function of horizontal grid-point spacing. For western boundary currents, the transports shown are the maximum barotropic streamfunction values in each of the subtropical gyres, relative to the coastlines. Points at extreme right with dashed lines to their left are from the $1 / 2^{\circ} \times 1 / 2^{\circ}$ run with biharmonic sub-gridscale diffusion. 


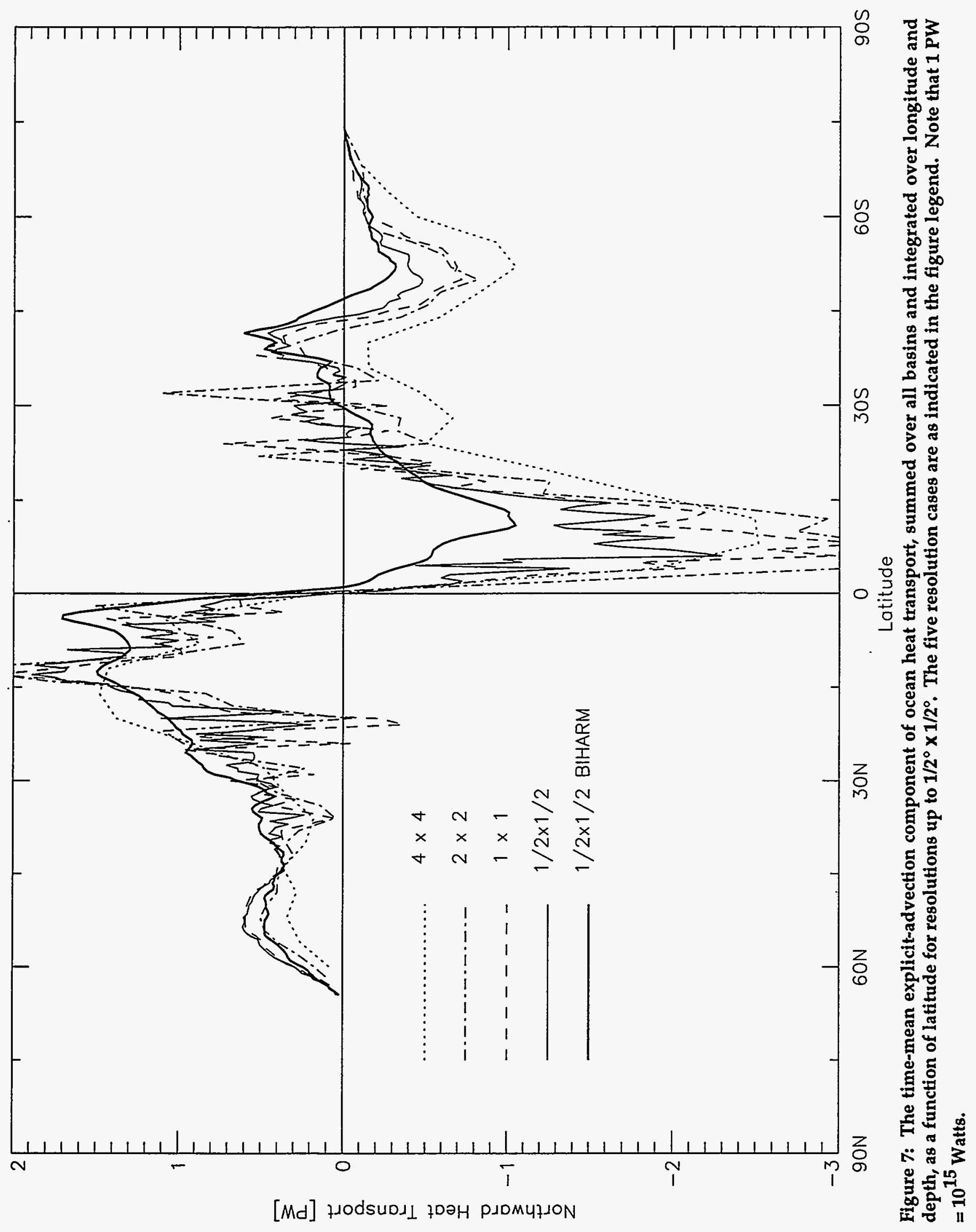




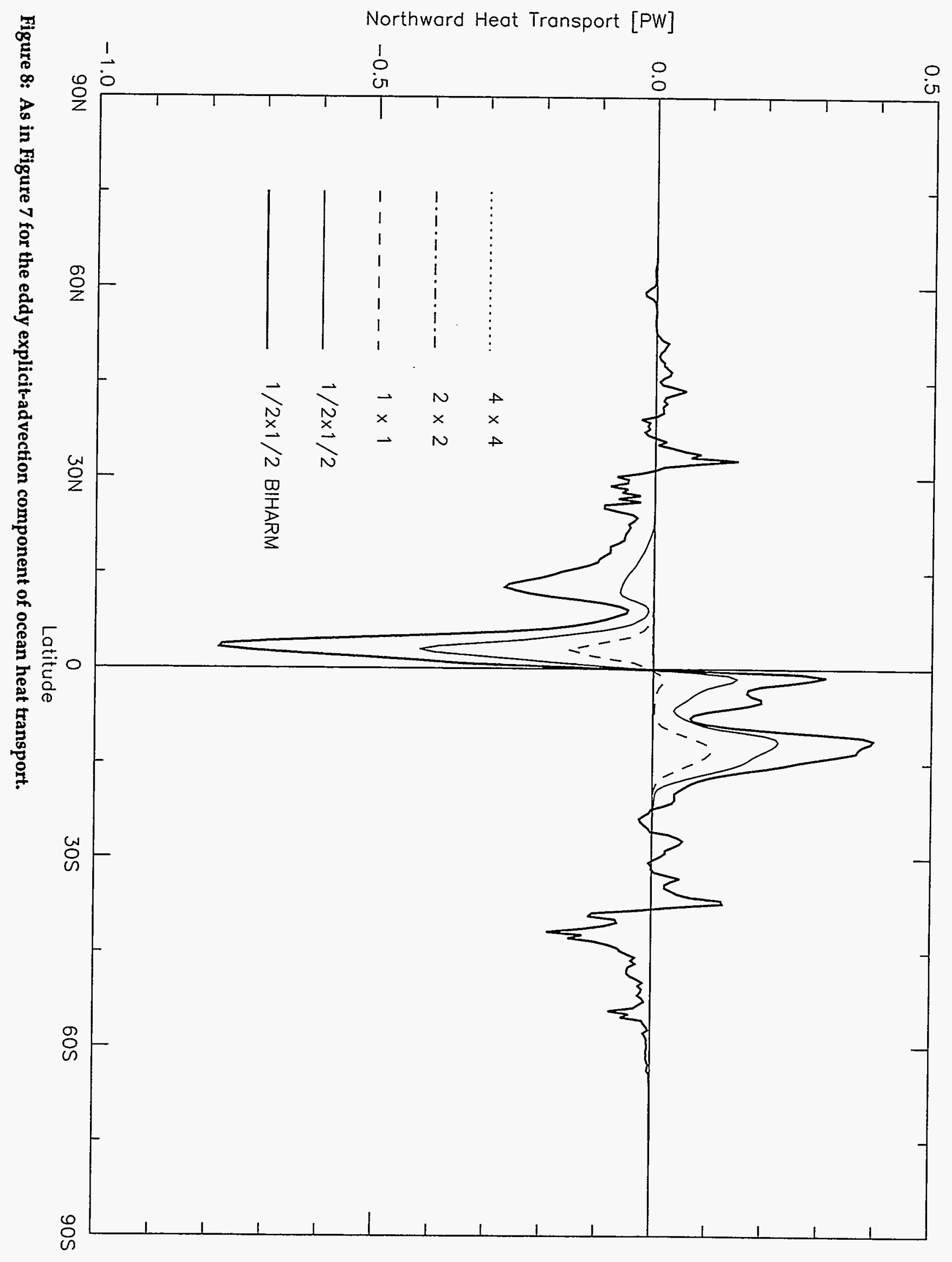




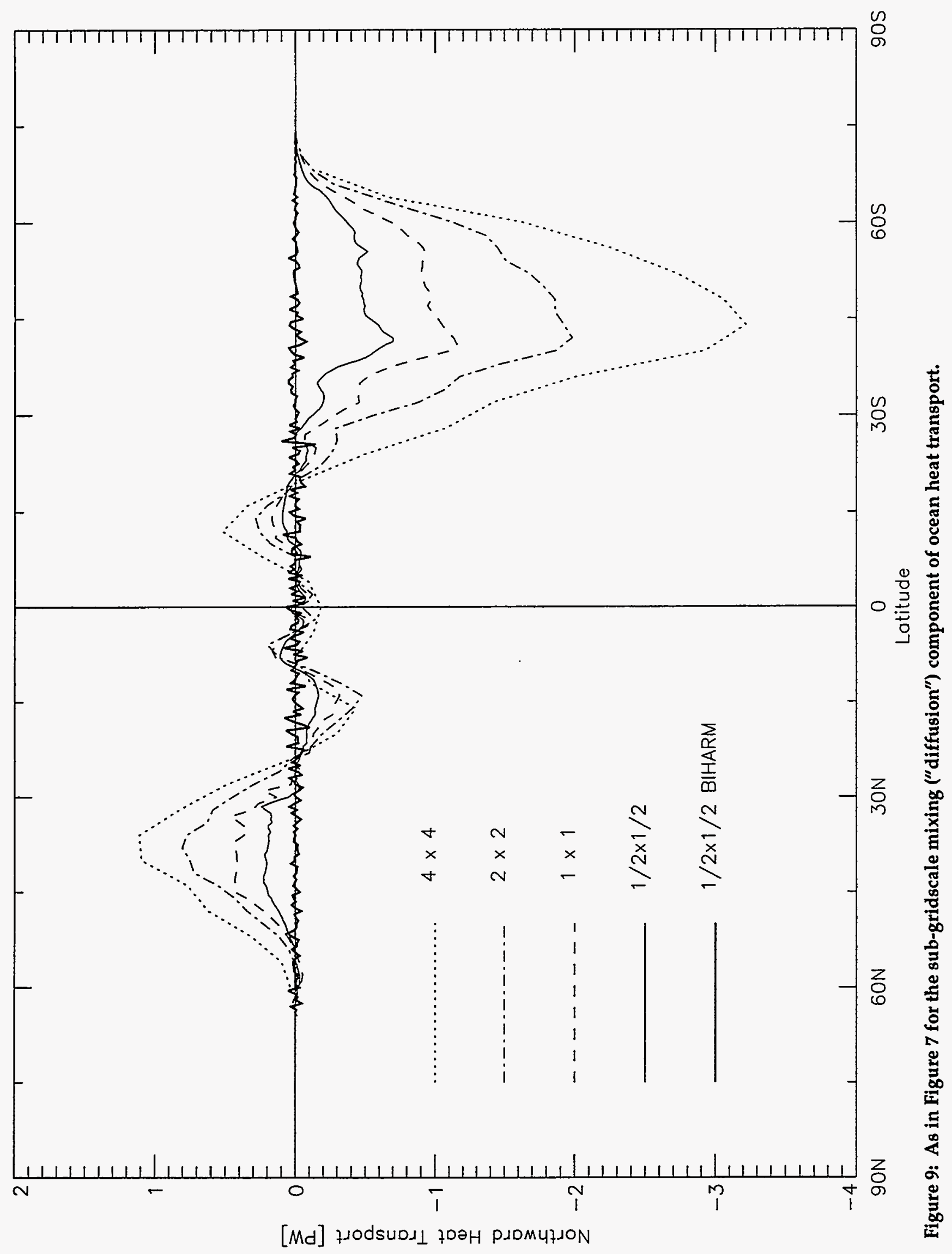




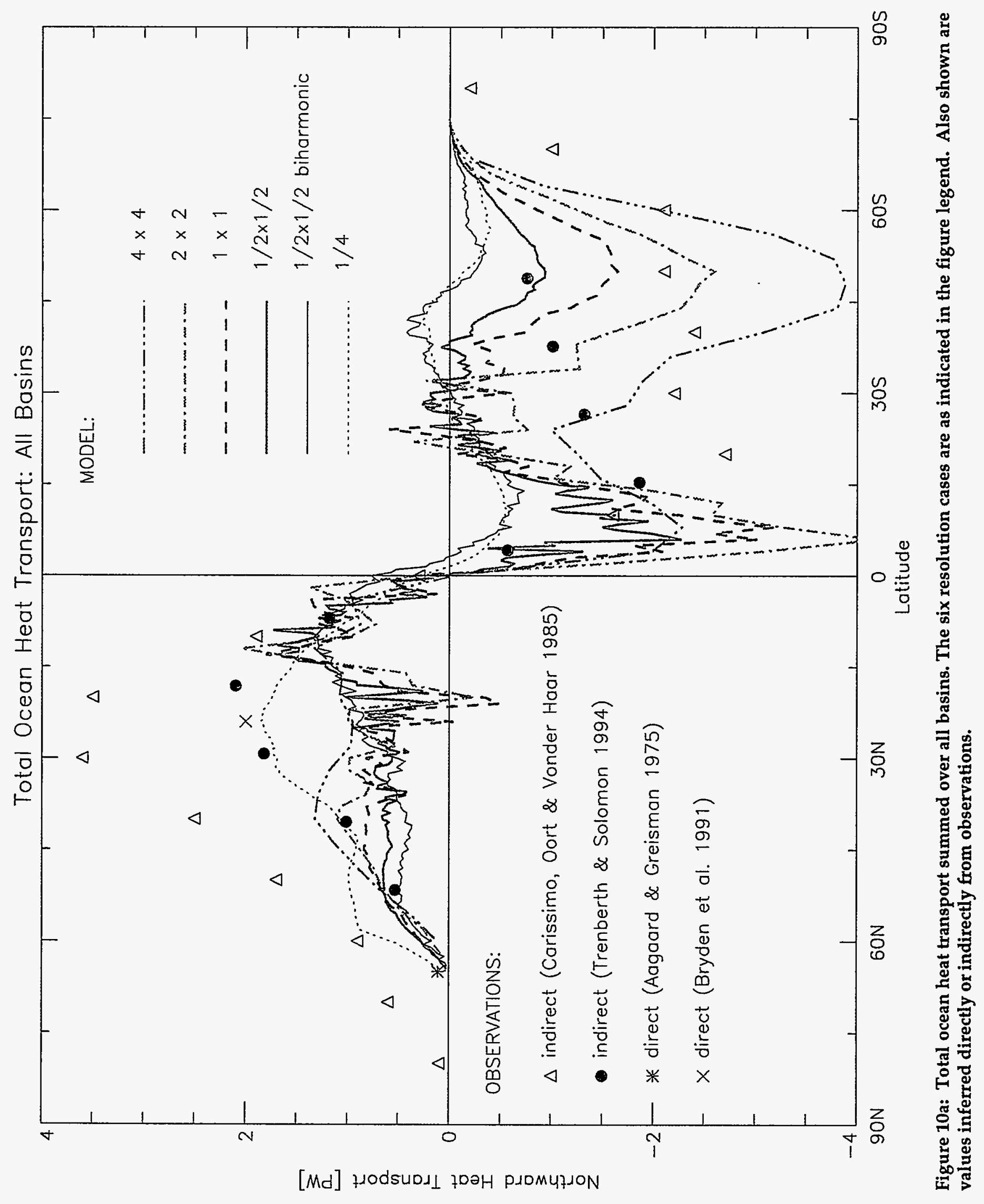




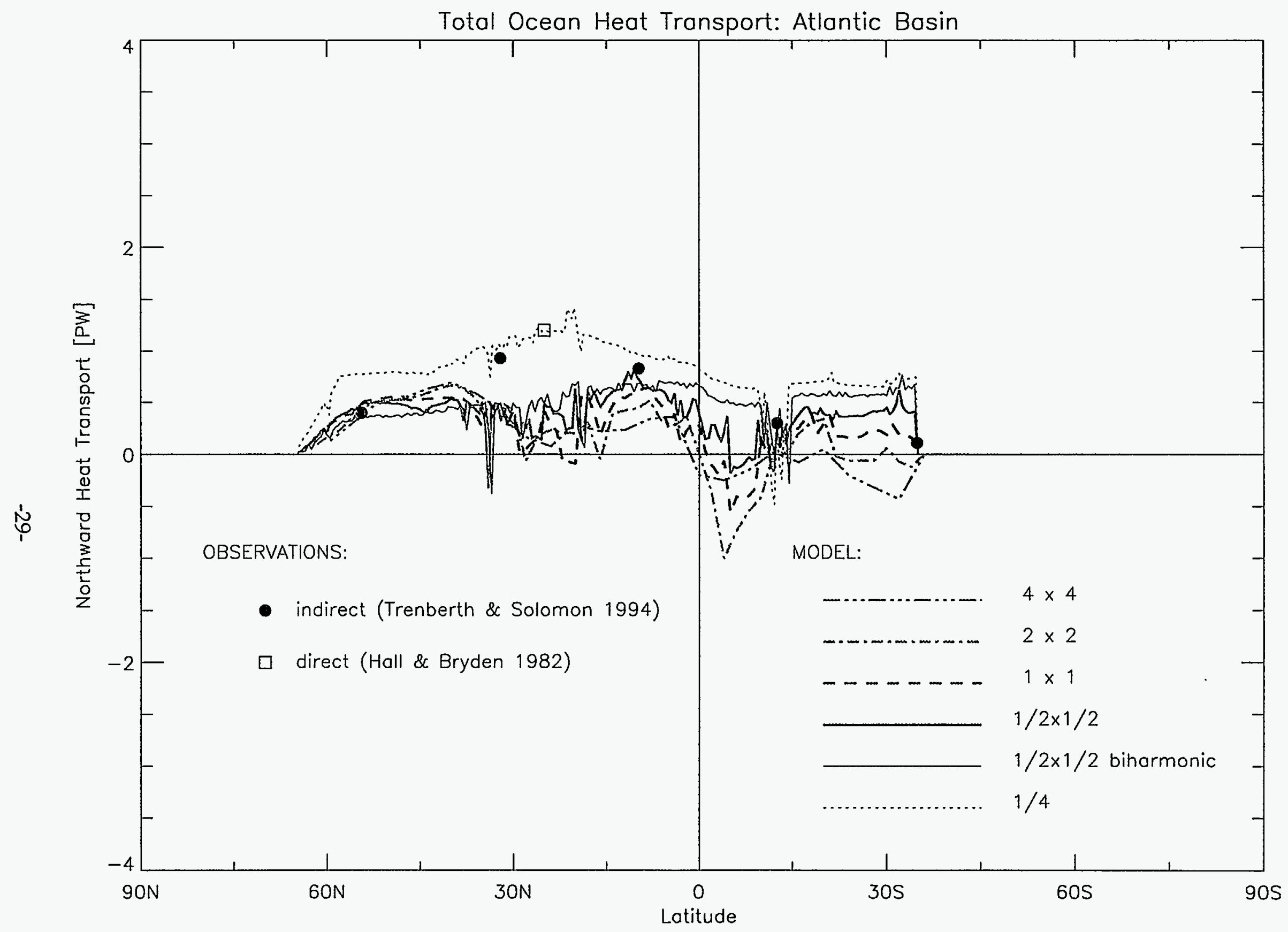

Figure 10b: Total ocean heat transport for the Atlantic basin only, for all resolution cases including $1 / 4^{\circ}$. The six resolution cases are as indicated in the figure legend. Also shown are values inferred directly or indirectly from observations. 


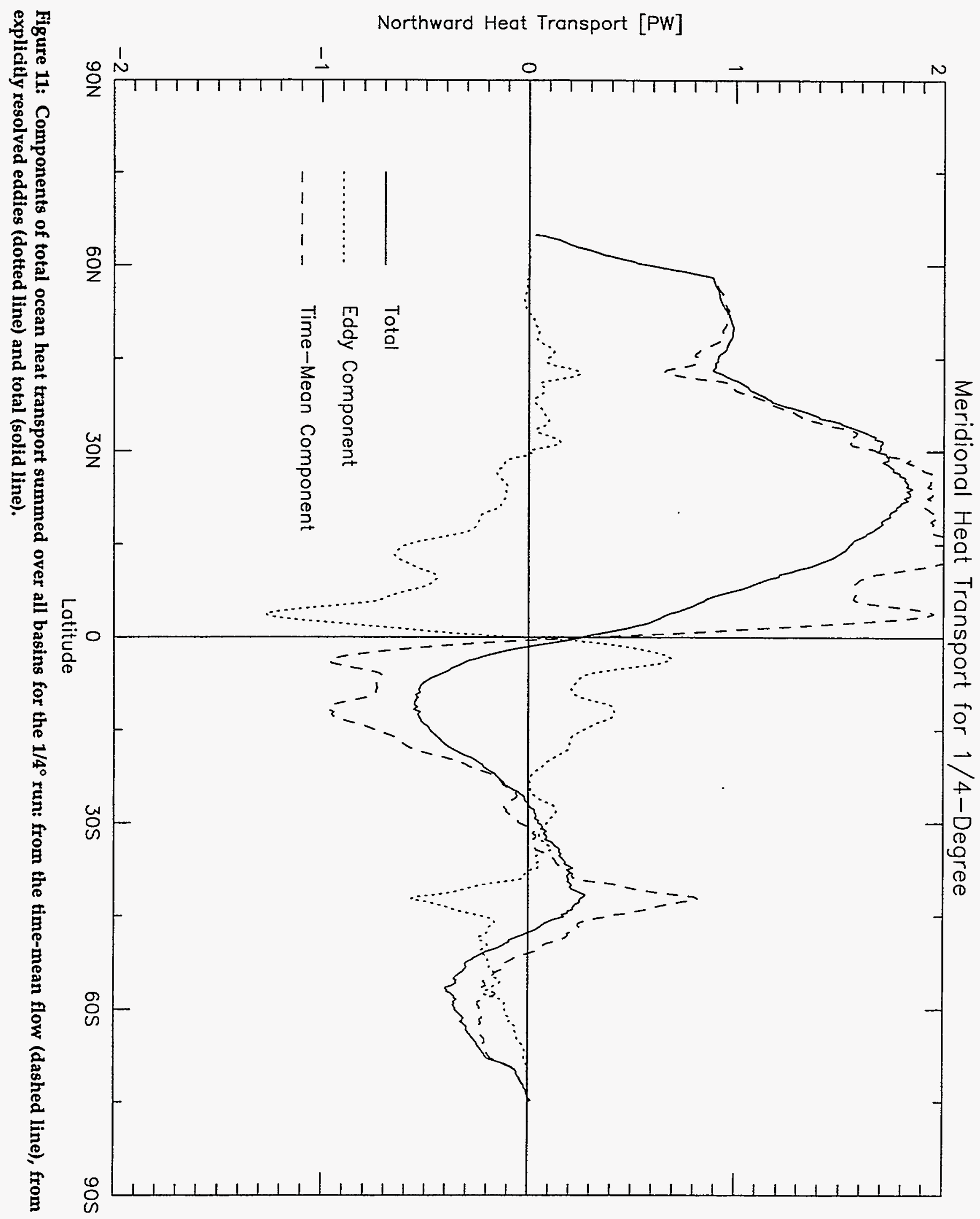




\section{PCMDI REPORTS}

Number

Title

Author(s)

$\underline{\text { Date }}$

1

$$
\begin{gathered}
\text { The Validation of Atmospheric } \\
\text { Models }
\end{gathered}
$$

2 Analysis of the Temporal Behavior

J. M. Slingo of Tropical Convection in the K. R. Sperber ECMWF Model

W. L. Gates

March 1992

J.-J. Morcrette

G. L. Potter

3 The Effect of Horizontal Resolution

P. J. Gleckler on Ocean Surface Heat Fluxes in

K. E. Taylor the ECMWF Model

4

Behavior of an Ocean General

C. Covey

April 1992 Circulation Model at Four Different Horizontal Resolutions

$5 \quad$ The Effects of Sampling Frequency

T. J. Phillips

on the Climate Statistics of the ECMWF General Circulation Model

W. L. Gates

K. Arpe

July 1992

August 1992

6 Sensitivity of Dynamical Quantities

J. S. Boyle

September 1992 to Horizontal Resolution in a Climate Simulation with the ECMWF Atmospheric General Circulation Model (Cycle 33) Intercomparison Project the ECMWF Model

S. L. Grotch

December 1992

January 1993 
L. Corsetti

\author{
The Use of General Circulation \\ Models in Detecting Climate \\ Change Induced By \\ Greenhouse Gases
}

11 Preliminary Validation of the Low Frequency Variability of Tropospheric Temperature and Circulation Simulated for the AMIP by the ECMWF Model

12

13 Simulation of the Indian and East-Asian Summer Monsoon in the ECMWF Model: Sensitivity to Horizontal Resolution

Statistical Intercomparison of Global Climate Models: A Common Principal Component Approach

14 Ocean Variability and its Influence on the Detectability of Greenhouse Warming Signals
B. D. Santer

U. Cubasch

U. Mikolajewicz

G. Hegerl
March 1993

April 1993
K. R. Sperber
S. Hameed
G. L. Potter
J. S. Boyle

S. K Sengupta

J. S. Boyle

November 1993

November 1993

B. D. Santer January 1994

U. Mikolajewicz

W. Brüggemann

U. Cubasch

K. Hasselmann

H. Höck

E. Maier-Reimer

T. M. L. Wigley 
Number

Date

15 Cloud-Radiative Effects on Implied Oceanic Energy Transports as Simulated by Atmospheric

P. J. Gleckler

March 1994

General Circulation Models

16

DRS User's Guide

D. A. Randall

G. Boer

R. Colman

M. Dix

V. Galin

M. Helfand

J. Kiehl

A. Kitoh

W. Lau

X.Z. Liang

V. Lykossov

B. McAvaney

K. Miyakoda

S. Planton

R. Drach

March 1994

R. Mobley

17 The PCMDI Visualization and

D. N. Williams

March 1994

Computation System (VCS): A

R. L. Mobley

Workbench for Climate Data

Display and Analysis

A Summary Documentation of the AMIP Models

T. J. Phillips

April 1994 